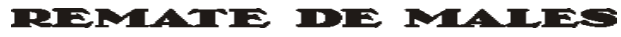

Campinas-SP, v.38, n.2, pp. 96o-989, jul./dez. 2018

\title{
A recepção de Garrett: o Brasil e a LITERATURA BRASILEIRA SOB O OLHAR DE UM CLASSICISTA ROMANTIZADO
}

\author{
Eduardo Melo França
}

Resumo: Pretendemos demonstrar como Almeida Garrett projetou o Brasil na sua obra e problematizou a possibilidade da emergência de uma literatura brasileira e original no século XIX.

Palavras-chave: literatura brasileira; Almeida Garrett; Romantismo.

Além de todos os aspectos políticos e econômicos que entrelaçam o passado do Brasil ao de Portugal, seria muito provável que o Brasil em qualquer medida ocupasse algum espaço na obra de Almeida Garrett por motivos familiares. Seu avô materno, o Sargento-Mor José Bento Leitão, viveu e fez fortuna no Brasil, em Pernambuco. Quando retornou viúvo para o Porto, levou consigo a "parda velha" Rosa de Lima, a criada de quem Garrett ouvia durante sua infância histórias sobre o Brasil. Ofélia Paiva Monteiro (1971, v. 1, p. 32) relata que:

Feito pelo Marquês de Pombal Deputado da poderosa Companhia dos Vinhos do Alto Douro (cuja sede era no Porto), [José Bento Leitão] se entregara a espaventosos atos de "brasileiro" com fortuna: construção da quinta e palacete do Sardão, doações à Misericórdia de Vila do Conde, vida farta de grande senhor, rodeado de criadagem numerosa, como a querer reproduzir na Metrópole o bulício da casa grande do Brasil das patacas.

1 Professor do Departamento de Letras da Universidade Federal de Pernambuco: <eduardomelofranca@gmail.com>. 
José Bento Leitão casou-se novamente em 1771, com D. Maria do Nascimento e Almeida, filha de José Fernandes de Almeida, que também enriquecera no Brasil. A filha de José Bento e de Maria do Nascimento é a mãe de Garrett, Ana Augusta. Isso significa que, pelo lado da mãe, Garrett possuía um avô e um bisavô "brasileiros de torna-viagem".

O pai de Garrett, António Bernardo da Silva, possuía um irmão, conhecido como Desembargador Leitão, que, com o encargo de criar a Comarca do Rio São Francisco "no último sertão da Província de Pernambuco” (MONTEIRO, 1971, v. 1, p. 65) em 1819, foi nomeado Desembargador Ordinário da Relação da Bahia. Por conta do processo de independência, sofreu hostilidades e no Brasil permaneceu apenas até 1824. Em suas memórias, publicadas em Lisboa em 1825, o Desembargador Leitão não poupa palavras contra os que, "[...] seguros de impunidade pela luciferina política de alguns homens tigres, diziam, com impudentes apupos e algazarras [...] tudo isto é nosso, que estes ladrões de Portugal nos vieram roubar" (MONTEIRO, 1971, v. 1, p. 65). O tio de Garrett, para chegar salvo a Portugal, precisou caminhar

[...] centenas de léguas por fragosas serranias e inóspitos gerais, com fomes, com sedes, debaixo de ardentíssimos céus, rompendo matas densíssimas, e cheias de ferozes onças e venenosas cascavéis, desbravando terras [...] e tendo não raras vezes de defender-se das setas dos gentios!!! (LEITÃO apud MONTEIRO, 1971, v. 1, pp. 65-66)

Lendo a evocação que Garrett (1904, v. 1, p. 798) faz à sua querida criada, ou escrava, Rosa de Lima, podemos supor que o Brasil que permeou o seu imaginário é doce, afetivo, grandioso e certamente herdado da memória que lhe veio da parte maternal da sua família:

Uma parda velha, a boa Rosa de Lima, de quem eu era o menino bonito entre todos os rapazes, e por quem ainda choro de saudades apesar do muito que me ralhava às vezes, era a cronista-mor da família, e em particular da capela e da quinta do Sardão, que ela julgava uma das maravilhas da terra e venerava como um bom castelhano o seu Escurial. Contava-me ela, entre mil bruxarias e coisas do outro mundo que piamente acreditava, que também naquelas coisas "se mentia muito"; que, de meu avô, por exemplo, diziam que tinha aparecido embrulhado num lençol passeando à meia-noite em cima dos arcos que trazem a água para a quinta: o que era inteiramente falso, porque "ela estava certa que, se o Sr. José Bento pudesse vir a este mundo, não se ia embora sem aparecer à sua Rosa de Lima” - E arrasavam-se-lhe os olhos de água ao dizer isto, luzia-lhe na boca um sorriso de confiança que ainda agora me faz impressão quando me lembra 
Seu tio, Frei Dr. Alexandre da Sagrada Família, o Bispo de Angra, possivelmente sua maior influência literária, cultural, moral e religiosa, visitou o Rio de Janeiro; assim como seu grande amigo e biógrafo Francisco Gomes de Amorim. Alguns colegas do tempo de Coimbra eram brasileiros, tais como Cassiano Espiridião de Mello Mattos, Rodrigo de Sousa da Silva Pontes Malheiro e Francisco Gomes Brandão Montezuma, além de Manuel Araújo Porto Alegre, que o escritor conheceu durante o exílio em Paris e com quem permaneceu mantendo correspondência. Além disso, deve-se contar que, apesar de nunca ter pisado no Brasil, "Garrett viveu no grande momento da Independência do Brasil, na época da publicação de vários textos que divulgavam por toda a Europa a flora, fauna, os costumes da ex-colônia, na época em que a ideia de nação a todos dominava” (RIBEIRO, 1999, p. 115).

Entre 1820 e 1826, o Brasil aparece na obra de Garrett de duas diferentes formas. Num primeiro plano, a ex-colônia é vista como um possível refúgio para os portugueses, no caso de o absolutismo voltar a Portugal. No segundo, são o colonialismo, a cobiça portuguesa pelo ouro e os males sociais vindos dessas práticas que fazem o Brasil aparecer como vítima. Entre esses textos, estão os que defendem o ideal de liberdade, tais como O Brasil liberto, O roubo das sabinas e Portugal na balança da Europa. Também dessa época data a ode "O ananás”. Apesar da referência exótica à paisagem e ao fruto tropical, como resume bem Aparecida Ribeiro, "Garrett utiliza a imagem apenas como comparante de símile: fecundo no exílio dos Açores, o ananás é como o sábio, que produz na solidão da 'ríspida ignorância' que o cerca, como Filinto Elísio que poetou 'nos pântanos de Haia'” (RIBEIRO, 1999, p. 116).

Sabemos que o Barroco se prolongou demasiadamente em Portugal. Segundo Aníbal Pinto de Castro, isso ocorre principalmente porque desde os quinhentos a Companhia de Jesus permaneceu com o monopólio do ensino das matérias literárias. Somente em 1746, Verney, com suas cartas "ficcionalmente" reunidas no Verdadeiro método de estudar, possibilita um primeiro abalo consistente no império Barroco português (CASTRO, 1999, p. 33). A partir de 1759, sob o tom iluminista do Marquês de Pombal, a Companhia de Jesus é dissolvida e em seu lugar o que se observa, segundo Aníbal de Castro (1999, p. 34), é um “retrocesso!":

Mandava o rei D. José que, para restaurar o estudo das Letras decaído durante o século anterior pela ação e método dos Inacianos, se tornava necessário repor o 
"método antigo (isto é, o do século XVI) reduzido aos termos símplices, claros e de maior facilidade, que se pratica atualmente pelas nações polidas da Europa”.

A partir desse momento, acentua-se um caráter normativo do código estético-literário, revalorizando o gosto renascentista, assim como as teorias vindas de Horácio e Quintiliano, com "[...] natural, embora não total, detrimento de Aristóteles e algum esquecimento de Cícero" (CASTRO, 1999, p. 35). O que poderia significar uma renovação poética, incentivando os autores portugueses numa direção de invenção e real renovação, mostra-se como um processo esterilizante de retrocesso às teorias e paradigmas renascentistas. Apesar de algumas tentativas, como a de Correia Garção, esse fracasso fica expresso no marasmo dominante e repetitivo da Arcádia Lusitana.

Pois bem, será nesse cenário que ocorrerá a primeira educação literária de Garrett. Ao longo de toda a sua obra, é possível identificarmos as marcas dessa formação clássica. Uma das formas pela qual sua educação classicista se efetivou é a leitura de Horácio. Segundo Francisco Gomes de Amorim (1881-1884), resta como prova disso uma edição da Arte poética, de Horácio, datada de 1814 e com a assinatura de João da Silva Leitão, ou seja, manuseada por um Garrett ainda adolescente.

No prefácio ao seu Catão, de 1821, há uma passagem que reflete a espontaneidade e naturalidade com a qual o pensamento e a educação clássica repercutem na sua pena. Comentando sobre as dificuldades, as obras que precisou ler e estudar e o esforço necessário para escrever a sua tragédia, repete, destacando em itálico, os versos da poética de Horácio (apud GARRETT, 1904, v. 1, p. 526) "com noturna e diurna” [Vos exemplaria graeca/ nocturna uersate manu, uersate diurna].

Mas, se Garrett não se desprende da experiência clássica, também novas formas e perspectivas lhe surgem e pedem defesas. ${ }^{2}$ Em 6 de maio de 1843, falando no Conservatório Real sobre o seu drama Frei Luís de Sousa, defende que uma tragédia moderna também é capaz de suscitar no espectador a mesma catarse aristotélica, causando-lhe terror e compaixão:

Repito sinceramente que não sei se o consegui; sei, tenho fé certa que aquele que o alcançar, esse achou a tragédia nova, e calçou justo no pé o coturno das nações modernas; esse não aceite das turbas o Trapsus consagrado, o bode votivo; não subiu ao carro de Tespis, não besuntou a cara com borras de vinho para fazer

2 Não é demais lembrarmos que os mais importantes contatos de Garrett com a estética romântica se dão em seus dois exílios na Inglaterra, entre 1823 e 1828. 
visagens ao povo, esse atire a sua obra às disputas das escolas e das parcialidades do mundo, e recolha-se a descansar no sétimo dia de seus trabalhos, porque tem criado o teatro da sua época. (GARRETT, 1904, v. 1, p. 771)

A ambivalência existe: clássico e moderno. Ao mesmo tempo em que nessa passagem notamos um tom modernizante e nacionalizante, com ares que desembocariam numa postura romântica, com a ajuda de Aníbal Pinto de Castro identificamos a persistência de Horácio no pensamento garrettiano:

Note-se que se trata, não de afirmar uma adesão à doutrina horaciana, mas de traçar os caminhos de uma modernidade dramática, recorrendo a formas metafóricas cunhadas a partir dos versos 275-277 da Poética horaciana:

"Ignotum tragicae genus inuenisse Camenae Dicitur et plaustris uexisse poemata Thespis

Quae canerent agerent que peruncti faecibus ora”

Ou na versão portuguesa de Rosado Fernandes:

"Diz-se que Téspis descobriu um género desconhecido da Camena trágica e transportou, em carros, as suas peças, que os atores cantavam e representavam de caras besuntadas com o mosto da uva". (CASTRO, 1999, p. 37)

Garrett somenteassimila o cristianismo sentimental de Chateaubriand e o relativismo histórico e nacional, teorizado por Madame de Stäel, associando-o a uma concepção de vida e à arte árcade e iluminista (SARAIVA; LOPES, 1982, p. 733). Sobram, por isso, na sua obra, passagens nas quais encontramos a insistência do pensamento clássico ou a crescente afirmação de propósitos nacionalistas e modernos - leiam-se, românticos.

Notamos, inclusive, certa ambiguidade, para não dizer confusão, quando Garrett trata da sua relação concomitante com o clássico e o moderno, entre a antiga escola na qual se formou e o novo gosto que tenta exercer para alcançar um público romântico (despreparado e em certa medida vulgar e inculto):

Claro está que toda esta busca não se processava sem algum desnorte e confusão. Nem admira que assim fosse. As leituras eram um tanto caóticas e as opiniões que nelas encontrava eram, as mais das vezes, díspares quando não confusas. Não andaria por isso longe da verdade quando confessava no prefácio de Mérope que a leitura de Alfieri e de Ducis lhe transtornara as ideias dramáticas, levando-o a perder "toda a fé nas crenças velhas", sem entender as novas nem acertar com elas. (CASTRO, 1999, p. 40) 
Garrett saberá fazer dessa mútua influência recebida pelos clássicos e românticos algo original e valioso. Dos clássicos, na maioria das vezes filtrados via os renascentistas, obtém o que lhe é necessário para traçar as linhas essenciais que determinam sua prudência, seu equilíbrio e sua capacidade de domar e disciplinar, mas sem sufocar uma alma de romântico, repleta de paixões, algumas amorosas, pessoais, e outras públicas, como cidadão, político e artista. E, o mais importante, saberá, através dos clássicos, da grande tradição, vislumbrar e valorizar aspectos que dizem respeito à ponderação e ao equilíbrio formal e ideológico, como também às memórias e tradições nacionais. Muitas outras incoerências, confusões, ambiguidades e misturas poderiam ser notadas e destacadas no aprendizado que Garrett obteve da leitura dos clássicos e dos modernos, mas sigamos ao ponto que cada vez mais nos interessa.

Muito diferente daquele Garrett simplista que no Bosquejo da história da poesia e língua portuguesa analisa a então incipiente literatura brasileira, tendo a cor local como critério fundamental, no prefácio que escreve ao seu Catão, encontramos exatamente este Garrett, meio clássico e meio moderno, formado pelas leituras renascentistas e já com um pé no Romantismo, que propõe a existência de um caráter literário nacional baseado não no pitoresco ou na cor local, mas no que ele nomeará de "rito". Notemos que inevitavelmente esse rito ao qual Garrett se refere nos lembra o que Machado de Assis chama de sentimento íntimo.

Antes do Catão já eu tinha feito muita tragédia, e comedias também; todas sem sabores. Exceto a Mérope - que talvez reveja e complete ainda - rasguei as outras: eram das tais inspiradas do reflexo estrangeiro, de portuguesas tinham as palavras; no mais pensadas em Grego, em Latim, em Francês, em Italiano, em Inglês - que sei eu!

No Catão senti outra coisa, fui a Roma; fui, e fiz-me Romano quanto pude, segundo o ditado manda; mas voltei para Portugal, e pensei de Português para Português e a isso atribuo a indulgência e boa vontade do público que me ouviu e me leu.

Foi uma regeneração para mim: foi caírem-me dos olhos as trevas de Tobias com os fígados do peixe trazido de tão longe. Não está nos nomes das pessoas a nacionalidade de um drama. Inês de Castro pode ser francesa, - e português Édipo; tudo depende do rito com que os evoca do jazigo para sobre o teatro, o sacerdote que faz os esconjuros. (GARRETT, 1904, v. 1, p. 524)

Abramos aqui um parêntese para notar que no Brasil Santiago Nunes Ribeiro (1974, p. 30), num discurso muito semelhante, também 
constata a possibilidade de, através de uma forma clássica, concluirmos uma expressão nacional:

No exame das poesias brasileiras cumpre não ver somente a exterioridade da arte, que muitas vezes apresenta as formas gregas e romanas; cumpre atender ao sentido oculto, à intimidade, ou pelo menos ao elemento da poesia tradicional que nela se acha combinado ao elemento americano.

Evidentemente esse ponto de vista sobre literatura nacional é conveniente a Garrett, já que sem maiores problemas se harmoniza com sua formação clássica. Entretanto, discordamos de Ofélia Monteiro quando diz que, por nutrir essa visão, Garrett não come o mesmo grave erro que alguns dos primeiros românticos brasileiros, como Gonçalves de Magalhães na Confederação dos Tamoios, que pensam fazer literatura nacional, simplesmente por acumularem nomes indígenas de personagens, da fauna, da flora e de objetos ou alusões sucessivas a costumes folclóricos. Para a autora, quando Garrett fala de uma literatura nacional portuguesa, ele não se refere à necessidade de um acúmulo de nomes, traços e cores de sua terra, "muito menos de uma sondagem da alma popular” (MONTEIRO, 1971, v. 1, p. 381). Ora, se Garrett, como artista, não comete o erro de condicionar a construção de uma nacionalidade literária ao descritivismo da paisagem, como crítico, a presença ou ausência da cor local é determinante nas análises que faz das obras brasileiras.

Assinado por Garrett, em 1826 sai Parnaso lusitano ou poesias seletas dos autores portugueses antigos e modernos, precedido pelo "Bosquejo da história da poesia e língua portuguesa”. Segundo Regina Zilberman (1998, p. 20), esta seria a primeira antologia de poemas em língua portuguesa. Publicado em seis volumes pela editora J. P. Aillaud, de Paris, o "Bosquejo" ocupa da página VII a LXXVII do primeiro volume da obra. Seus tomos são divididos por gêneros literários, sendo o primeiro dedicado à poesia épica; o segundo, aos poemas descritivos e didáticos, bucólicos e herói-cômicos; o terceiro e o quarto, aos epigramáticos e líricos; o quinto, à poesia dramática; e o sexto e último tomo, aos satíricos, em que aparece $O$ Hissope, de Antônio Dinis da Cruz e Silva.

Os poetas brasileiros que constam no volume I do Parnaso são: Basílio da Gama ("Lindoia") e Santa Rita Durão ("Moema”). No volume II: Francisco de Melo Franco ("A estupidez triunfante em Coimbra”). No volume III: Cláudio Manuel da Costa ("Nise! Nise! Onde estás? Aonde espera”; "Breves horas, Amor, há que eu gozava"). Nos volumes III e IV: Domingos Borges de Barros ("A flor da saudade”; "À noite”; “À virtude"), 
José Bonifácio de Andrade e Silva ("Os fachos pelos ares sacudindo"; "Adeus, fica-te em paz Alcina amada”; "A criação da mulher"; "À poesia”; "À amizade"); e Tomás Antônio Gonzaga ("O contentamento"; "O perjúrio"; "O retrato"; "Todos amam"; "Recordações”). No volume V: Paulo José de Melo (com a epístola "Círio"). O padre Sousa Caldas aparece no volume II, com "As aves"; no volume IV, com os salmos "Beatus vir qui non abiit" e "Quare fremuerunt gentes", e as odes "A existência de Deus", "O homem selvagem" e "Pigmaleão"; e no volume V com a "Carta a João de Deus Pires Ferreira”. Nem todos esses poetas são analisados no "Bosquejo".

Sabe-se que a participação de Garrett no "Bosquejo" é controversa. No "Ao leitor", que abre o seu Tratado de educação, lemos a seguinte advertência:

Já em outra parte protestei que nada meu tinha no Parnaso lusitano que publicou o Sr. Aillaud, livreiro em Paris, senão o resumo da história literária de Portugal que vem no princípio do primeiro tomo daquela coleção. É certo que arranjei o sistema e plano da obra, que escolhi os autores e peças; mas ausentando-me de Paris antes de completa a impressão do primeiro volume, um homem por nome Fonseca, a quem de minha algibeira paguei para rever as provas, tomou a liberdade de alterar tudo, introduzindo na coleção produções ridículas de gente desconhecida, e que eu nunca vira, omitindo muitas das que eu escolhera, enxovalhando tudo com notas pueris e indecentes, errando vergonhosamente até o índice de matérias que eu preparara para cada volume, $\mathrm{e}$ introduzindo uma ortografia galega que faz rir a gente e que está em contradição com as regras que eu na prefação estabelecera [...] - Repito esta declaração para que me não atribuam as grossas tolices e grossas má criações que emporcalham aquela obra, que tão bela podia ser. (GARRETT, 1904, v. 2, p. 282)

Garrett confirma o que mais nos interessa. Entre o que escreve (e o que por ele escrevem), o resumo da história literária de Portugal definitivamente é de sua autoria. Nele estão as ideias que a seguir discutiremos. No restante, também o panorama geral da obra parece por ele ter sido concebido, já que nesse mesmo "Ao leitor" afirma que permanecerão "nessa obra as mesmas regras que para a do Parnaso lusitano tinha estabelecido" (GARRETT, 1904, v. 2, p. 282). Teófilo Braga (1905), organizador da sua obra, diz que o plano geral é de Garrett, embora alterado por José da Fonseca e que o volume VI não teria sido feito por Garrett.

Diante de nossas intenções, não podemos deixar de destacar o último parágrafo do "A quem ler", que precede o "Bosquejo". Nessa passagem, Garrett expõe seus objetivos e critérios para a realização do estudo: 
Julgo haver prestado algum serviço à literatura nacional em oferecer aos estudiosos de sua língua e poesia um rápido bosquejo da história de ambas. Quem sabe que tive de encetar matéria nova, que português nenhum dela escreveu, e os dois estrangeiros Bouterwek e Sismondi incorretissimamente e de tal modo que mais confundem do que ajudam a conceber e ajuizar da história literária de Portugal; avaliará decerto o grande e quase indizível trabalho que me custou esse ensaio. Não quero dá-lo por cabal e perfeito; mas é o primeiro, não podia sê-lo. Além de que, a maior parte das ideias vão apenas tocadas, porque não havia espaço em obra de tais limites para lhe dar o necessário desenvolvimento. (GARRETT, 1998, p. 28, grifo nosso)

Em outras palavras, Garrett, “[...] em seu longo ensaio - menos de análise histórica do que de preocupação estética e de conteúdos explorados pelos escritores" (VIEIRA, 2002, p. 128), primeiramente, não se propõe a fazer outra coisa senão escrever uma história da literatura portuguesa, numa perspectiva assumidamente nacional e, depois, corrigir os erros encontrados nas obras de Bouterwek e Sismondi.

Embora no "Bosquejo" encontremos algumas rápidas análises formais sobre poemas escritos por brasileiros, tudo indica que verdadeiramente lhe interessa mostrar que esses autores resvalaram na possibilidade de construir uma literatura autenticamente brasileira, mas permaneceram ligados às imagens e aos códigos culturais e estéticos de Portugal e Europa. ${ }^{3}$ Além disso, vemos que aos olhos de Garrett (1998, p. 56) a literatura brasileira não passa de um desdobramento da portuguesa, podendo ela no máximo "enriquecer" o tronco principal, lusitano, do qual nasceu e ao qual permanece ligada:

Agora começa a literatura portuguesa a avultar enriquecer-se com as produções dos engenhos brasileiros. Certo é que as majestosas e novas cenas da natureza naquela vasta região deviam ter dado a seus poetas mais originalidade, mais diferentes imagens, expressões e estilo, do que neles aparece: a educação europeia apagou-lhes o espírito nacional: receiam de se mostrar americanos; e daí lhe vem uma afetação e impropriedade que dá quebra em suas melhores qualidades.

Não é difícil entendermos e concordarmos que, quando Garrett fala de um rito, tal como posto no prefácio ao Catão, ele propõe que a nacionalidade de uma obra esteja não necessariamente nas imagens ou

\footnotetext{
3 Fazemos essa distinção, pois os próprios autores portugueses, durante o Romantismo, tentavam definir a essencialidade e os traços mais marcantes da literatura portuguesa, diferenciando-a da literatura que vinha sendo produzida nos demais países europeus, primeiramente na Espanha e depois na França. Esse procedimento é facilmente constatado no Bosquejo.
} 
mesmo num resgate histórico nacional, mas na possibilidade de sua trama e personagens evocarem e expressarem, através de suas motivações, justificativas e construções psicológicas, um modo de ser, pensar e agir português.

Eis um contrassenso. Se Garrett afirma que a sua concepção de literatura nacional escapa do descritivismo local, como justificar que elogie e considere os poemas de Basílio da Gama e Santa Rita Durão como as primeiras tentativas de nacionalização da literatura brasileira apenas por apresentarem um nativismo de descrição da cor local? Se, como ele próprio afirma, o que define a nacionalidade de uma obra é isso que ele chama de rito, e não uma ambientação realista e acumulativa de elementos históricos e locais, Ivan Teixeira (1999) mostra que os projetos que motivam o Caramuru e $O$ Uraguai não estão de forma alguma atrelados a uma concepção, projeto ou construção de identidade e literatura brasileiras. ${ }^{4}$ Depois, em ambos os casos, não apenas os códigos literários são europeus, mas também a cor local aparece em ambas as obras como contingências históricas pouco significativas. O propósito dos dois poemas não é o de contar a história do Brasil, de seus habitantes ou de qualquer aspecto que venha a ser propriamente brasileiro e nacional, mas discutir e elogiar atitudes e ideologias relacionadas à Companhia de Jesus e ao Marquês de Pombal.

Não há qualquer possibilidade de encontrarmos em Basílio da Gama ou Durão algo que expresse esse tal rito brasileiro, já utilizando a terminologia garrettiana. Qualquer traço da realidade brasileira que apareça nesses dois livros somente terá sido concebido e utilizado pelos seus autores como munição ilustrativa e argumentativa. Ferdinand Denis ou Garrett não o mencionam, mas é difícil imaginar que ignorassem que o épico de Durão não é outra coisa senão uma reafirmação dos valores católicos, os únicos verdadeiros e que deverem se sobrepor a qualquer tipo de insurgência política ou indigenista; e que o de Basílio da Gama não é motivado por outra coisa senão a vontade de atacar a sua antiga ordem religiosa, a Companhia de Jesus, e louvar os atos do Marquês de Pombal.

É preciso também diferenciar, por exemplo, a concepção garrettiana de literatura nacional e suas propostas para uma literatura brasileira da

4 É importante que se diga que Garrett não acredita na possibilidade da existência de uma literatura brasileira autônoma. Esta, ainda que alcance um grau de nacionalização, pela valorização da cor local, nunca será mais do que uma faceta regionalizada de uma literatura maior da qual nasceu, a portuguesa. 
crítica que José de Alencar faz à Confederação dos Tamoios. O argumento de Alencar, independentemente de concordarmos, é muito claro. Afora o indianismo, sobra no poema de Gonçalves de Magalhães um artificioso classicismo e falta "arte" para descrever a natureza brasileira e os costumes indígenas, além de unidade poética e narrativa, apuro estético e musicalidade. Em relação ao modelo poético adotado por Gonçalves de Magalhães, Alencar (1856, p. 25) critica a filiação épica dele, pois seria inadequada: "A forma com que Homero cantou os gregos não serve para cantar os índios”. Em poucas palavras, para Alencar, além dos seus julgamentos estéticos, Gonçalves de Magalhães não é capaz de fazer o que Gonçalves Dias e ele próprio viriam a fazer, principalmente em Iracema: falar sobre o Brasil de um modo que não fosse o europeu.

Num primeiro momento parece que os olhares de Alencar e Garrett convergem, uma vez que o crítico português também pode acusar em $A$ confederação a falta desse rito. No entanto, se assim o for, ainda permanecerá em aberto a razão de seus elogios a Basílio da Gama e Santa Rita Durão. Isso porque os dois poemas não apresentam o tal rito, mas simplesmente um descritivismo que, como vimos na sua apresentação do Catão, não seria o fundamental.

Se o que lhe importa é o simples acúmulo de descrição local, $O$ Uraguai, Caramuru e A Confederação serão considerados fundadores da literatura brasileira. De outra forma, se seu critério fundamental é o rito, nenhum dos três é capaz de transmitir uma nova condição literária que reflita a ideia de Brasil e a condição de ser brasileiro. Além do que, se o seu rito é tão imprescindível, por que não é ele mencionado no "Bosquejo", na seção dedicada à literatura brasileira, deixando de outra forma pesar na cor local todas as possibilidades para a construção de uma literatura nacional?

Temos uma hipótese. A exuberante cor local para Garrett possui uma dupla função. Baseado nas ideias de Denis, ela serve como tema para a construção da literatura brasileira, mas também como motivo estético, através do qual violentará o marasmo acinzentado do Neoclassicismo português. Para o seu aborrecimento, também os portugueses preferem imitar Sannazaro, Boscán e Garcilaso e "copiaram pouco do vivo da natureza, que tão bela, tão rica, tão variada se lhes apresenta por todas as quatro partes de que em breve constou o mundo português" (GARRETT, 1998, p. 32). 
De qualquer forma, se em vez da cor local os primeiros árcades brasileiros fossem analisados no "Bosquejo" sob a égide mais sofisticada e sutil do rito, teríamos conclusões semelhantes, mas com premissas diferentes. A literatura brasileira permanece vista como um prolongamento regionalizado da portuguesa. Não porque lhe falte a cor local ou o brilho floreado das matas selvagens americanas, mas porque muito provavelmente, e com razão, Garrett não reconheceria na poesia de nenhum desses poetas um modo de ser brasileiro, ou seja, um rito nacional. De 1821, ano da publicação do Catão, para 1826, quando veio a público o "Bosquejo", vemos a passagem de um Garrett que concilia, por meio do rito, o universal clássico com o modo de ser nacional, para outro que, ao menos temporariamente, adota como critério para sua história da literatura portuguesa a cor local e o uso da língua. ${ }^{5}$

Em nenhum momento, os poetas que costumamos enxergar como árcades brasileiros, listados no Parnaso e no "Bosquejo", são incorporados ao corpus da literatura portuguesa. A situação é ambígua, pois todos são expostos a partir do paradoxo de terem nascido no Brasil, serem brasileiros, mas incapazes de fazer uma literatura "autenticamente" brasileira. Segundo Garrett, a literatura produzida no Brasil permanece ligada à portuguesa mesmo quando deixa de ser dela um desdobramento, uma continuidade e passa a ser um adendo, uma variante. Isto é, manter-se-á o vínculo de dependência, ainda que seja uma variante completamente diversa, expressamente tropical e evidentemente não mais reflita a cultura portuguesa. A produção brasileira, como disse Aparecida Ribeiro (1999, p. 117), é "encarada como uma variante regional da literatura portuguesa e os seus autores como brasileiros, sim, pelo nascimento ou objeto da poesia, mas portugueses pela língua em que escreviam".

Talvez por isso Arnaldo Saraiva (2002, p. 7) diga que Bento Teixeira, Gregório de Matos, Cláudio Manuel da Costa, Tomás Antônio Gonzaga e tantos outros poetas que constituem o cânone brasileiro, somente por "preconceito, ignorância ou distração moderna podem ser expulsos do cânone português". Podemos também notar que a apreciação crítica e o elogio à forma que por ventura Garrett faz aos brasileiros acabam por disputar espaço com a sua concepção da necessidade de uma poesia verdadeiramente nacional. Seu principal argumento é que mesmo

5 É no seu poema "Camões" que Garrett melhor expressa esse equilíbrio entre o aprendizado clássico e a modernidade nacionalizante romântica. 
nos melhores poemas o resultado é abalado pela insuficiência de uma abordagem verdadeiramente americana da cor local.

O "Bosquejo" organiza-se numa disposição diacrônica; as obras são expostas segundo uma linha cronológica, independente dos gêneros. Seu fluxo não segue numa tendência constantemente crescente, sendo, segundo Garrett, naquele momento a situação literária portuguesa desalentadora. Figuras externas à literatura, como D. João I, D. Manuel e o Marquês de Pombal aparecem como personalidades que influenciaram os diferentes períodos literários. Dentro de cada um desses períodos, são apontadas as influências determinantes de alguns escritores, como Gôngora e Marino no século XVII e Bocage no final do século XVIII, além das características literárias dominantes de cada época; a mais importante delas, o uso da língua portuguesa ou espanhola, sendo a primeira elogiada e a segunda, repudiada. Por isso, estranhamente aparecem desvalorizados por Garrett os autores barrocos e exaltados muitos dos classicistas e árcades lusitanos.

Ao longo de todo o ensaio, Garrett empreende um crivo que valoriza os que preservavam a expressão, a língua e o estilo português e ataca aqueles que se deixavam influenciar por línguas e literaturas estrangeiras. Ele anota que durante o Barroco português os excessos verbais e metafóricos, caracterizados como cultismo, vêm como uma torrente nefasta da Espanha, particularmente inspirados pelo poeta D. Luís de Gôngora. Entende-se a rejeição de Garrett pela penetração do gongorismo nas letras e na intelectualidade portuguesa, pois, como diz Segismundo Spina (apud VIEIRA, 2002, p. 131), teria sido ele o “[...] responsável por toldar a clareza da frase lusa, a cristalina legitimidade da expressão tradicional”.

Tal como Garrett, Herculano reclama que os séculos XVII e XVIII em Portugal foram marcados por um enorme prejuízo literário. No entanto, diferenciando-se do autor de D. Branca, pelo menos num primeiro instante, sua queixa não se dá expressamente pela ausência de uma nacionalidade literária. O problema é posto por Herculano num plano formal e estilístico. A literatura portuguesa, sofrendo de um excesso metafórico trazido pelos ventos cultistas, preocupa-se excessivamente com a forma e menos com as ideias:

A convicção de uma verdade literária produziu nos séculos XVI e XVII um erro na Itália, que, estendendo-se à Espanha e a Portugal, transviou da legítima direção todos, ou quase todos os escritores da época chamada do seiscentismo. Sentiu-se que a metáfora, a mais bela de todas as figuras poéticas e oratórias, a mais repetida, a mais necessária mesmo nos discursos comuns da vida, 
abundava por isso nos bons escritores clássicos e modernos, que já nesse tempo ilustravam a Europa: viu-se que as passagens belas ou sublimes de Horácio, Píndaro e Virgílio, de Dante e Ariosto, deviam-lhe em grande parte a sua beleza e sublimidade, e isto era certo; inferiu-se daí que a metáfora era o principal e talvez o único meio da poesia e eloquência, e que ela devia revestir todas as imagens e sujeitar ao seu império todos os gêneros, todos os estilos, e isto foi um erro: a vertigem metafórica se apossou dos poetas e oradores, e, por uma consequência natural, o fundo das ideias esqueceu e só se olhou para as formas: à sombra d'esta mania prosperavam os conceitos e as agudezas, chegando as letras a cair numa barbárie, que tanto mais irremediável parecia por ser filha da civilização literária já exagerada. O Zodíaco soberano, Os cristais d'alma, A Fênix renascida e outros muitos escritos d'esse tempo, são lamentáveis monumentos da corrupção de gosto a que chegou Portugal no princípio do décimo oitavo século. (HERCULANO, 1909, p. 4)

Por outro lado, apesar de Garrett elogiar nos classicistas portugueses a tentativa de manter vivo um diálogo com a cultura clássica, procurarem determinar e descrever os elementos definidores da paisagem portuguesa que os circundavam e não se deixarem ser afetados pelo gongorismo vindo da Espanha, como os barrocos - ou por galicismos, como muitos de seus contemporâneos -, os setecentistas sofrem duras críticas quando Garrett neles constata em vários momentos uma tendência à imitação estéril dos clássicos. Essa postura de repulsa à imitação perpassa todo o "Bosquejo". Por esse motivo, Camões, nas suas palavras o "Homero das línguas vivas", ocupa no cerne do seu pensamento um lugar de destaque. Ele soube ao mesmo tempo reconhecer e superar a antiguidade, assim como também observar o seu tempo, com novas ideias e formas.

Juntamente com o argumento da língua, aparece constantemente em todas as suas análises, de obras portuguesas e brasileiras, a demanda por um "espírito nacional". Ora, isso o leva a um grave erro de julgamento. Apesar de a cor local ou o nativismo serem conceitos estabelecidos a partir do Romantismo, particularmente em Portugal desde Madame de Stäel (ZILBERMAN, 1997, p. 6o), Garrett os impõe como balança para todas as obras do passado. Regina Zilberman resume bem um dos principais critérios de análise e valoração utilizados por Garrett na análise que faz das obras que compõem o Parnaso:

Ainda que examine a linguagem poética desde a terminologia da retórica, Almeida Garrett entende a língua como elemento definidor da nacionalidade, sendo o escrever em português valor estético que recomenda as obras; somese a essa visão linguística a rejeição das influências e da imitação, e ter-se-á a sintonia do autor com os pressupostos da estética romântica. (ZILBERMAN, 1997, p. 6o) 
Importante que se diga que a procura pela cor local que encontramos em Garrett e Denis possui as mesmas fontes: Bouterwek e Sismondi. Estes também apresentam nas suas análises como principal valor estético a presença da cor local. Somando as ideias de Denis ao contexto romântico - no qual a concepção de nacionalidade assume um status privilegiado -, a cor local, enquanto tema e fundamento nacional, surge para Garrett como a solução mais rápida e eficiente na tentativa de simultaneamente se desvencilhar do Classicismo e criar uma linha delimitadora e constitutiva daquilo que pode ser considerado como literatura portuguesa.

Garrett funda a história da literatura portuguesa (ZILBERMAN, 1997, p. 63). Para isso, retrospectivamente, precisa dissociar a literatura portuguesa da espanhola e, prospectivamente, ainda que não seja seu projeto consciente, da literatura brasileira. Para que a literatura brasileira se admita diferente da portuguesa é preciso que esta se defina e delimite seus perímetros formais, históricos e temáticos. Nesse exercício de constante diferenciação e caracterização da literatura portuguesa, seu argumento-chave é explicitamente a tradução da cor local e o uso do idioma português. Sabemos que o processo de formação da literatura brasileira não se dá por uma autoconstrução, definição ou análise, mas a partir de uma tentativa de diferenciação externa, diante da literatura portuguesa.

Portanto, se a história da literatura brasileira só pode existir autonomamente a partir do momento em que também uma história da literatura portuguesa se estabelece - isto é, os dois corpos nitidamente dissociados-, podemos dizer que Garrett, ainda que não intencionalmente, é quem possibilita que a literatura brasileira, vislumbrando os limites da portuguesa, se sinta capaz de dela se diferenciar, instituindo as marcas que supostamente lhe são essenciais e não compartilhadas com a portuguesa. As linhas que podem construir o Brasil como uma nação estão intrinsecamente relacionadas àquelas que definem a substância da nação portuguesa. Nesse momento, é impossível que um se implique nessa questão sem que o outro venha a reboque: "O problema da modernidade da literatura portuguesa é inseparável do problema da delimitação nacional da literatura brasileira" (BAPTISTA, 2005, p. 25). O processo de nacionalização da literatura brasileira ocorre porque ela se separa da portuguesa, mas também porque a portuguesa dela se separa. "Ambos os movimentos foram ativos, e ambos afetaram o destino das duas literaturas" (BAPTISTA, 2005, p. 26). 
Se o valor da cor local, presente no "Bosquejo", parece tão valorizado ao ponto de influenciar os próprios críticos brasileiros, como Joaquim Norberto, Pereira da Silva e Adolfo Varnhagen, nas obras publicadas entre 1840 e 1850 também não é difícil percebermos que para Garrett, como também para Pinheiro Chagas, a necessidade da incorporação da cor local é na verdade um falso obstáculo para a autonomização da literatura brasileira. Além de tudo e de todos, há sempre na retaguarda a ideia do idioma português como uma posse de Portugal. Conscientemente, Garrett considera impossível a existência de uma literatura brasileira e autônoma. A língua, para ele, não é apenas um meio através do qual um povo se expressa. Mais do que isso, ela é o meio pelo qual se atualiza e se transmite uma série de elementos constitutivos e fundadores de um povo, cultura e nação: a memória, os mitos, as crenças, as tradições, as religiões e todos os códigos psicológicos e sociais. A língua é a mais evidente e ao mesmo tempo profunda expressão de uma cultura. Portanto, por mais que os brasileiros introduzam em suas produções poéticas novas formas, estilos e imagens, ainda assim estarão submetidos às regras gramaticais e a tudo aquilo que se expressa como cultura portuguesa e que se faz presente no uso da língua.

Diante desse cenário, a busca por uma autonomia literária brasileira parece estar num beco sem saída. Afinal, mesmo que seus poetas sigam à risca a simplória cartilha da cor local, permanecem numa posição de relativa subserviência aos ditames portugueses. Isso porque, aos olhos de Garrett (1984, v. 4, p. 54), a condição portuguesa de proprietária do idioma lhe outorga um lugar diferenciado em relação a todas as outras literaturas de língua portuguesa:

\footnotetext{
Sim, senhor, queria o Brasil uma poesia brasileira - isto é, portuguesa legítima no desenho, americana no colorido. Camões fincou a língua, a poesia e a literatura de todos os povos que descenderam da grande família lusitana. É preciso saber granjear, no nosso terreno, a parte da herança que nos tocou ao fazer partilhas.
}

Infelizmente, é evidente que a ideia garrettiana de rito passa longe de qualquer frase que se leia no "Bosquejo". Aquela possibilidade de se construir uma literatura nacional a partir da apreensão e expressão de um modo de ser particular, possivelmente nacional, é sobreposta pela cor local e o uso do idioma.

A força do "Bosquejo", um estudo que potencialmente lança as bases para a fundação de duas histórias literárias, a portuguesa e a brasileira, é 
capaz de alcançar elevadas alturas e tocar autores e pensadores de grande rigor, como Machado de Assis. Em 1858, no "Passado, presente e futuro da Literatura”, Machado, ainda fazendo eco às palavras de Garrett, escreve que "Gonzaga, um dos mais líricos poetas da língua portuguesa, pintava cenas da Arcádia, na frase de Garrett, em vez de dar uma cor local às suas liras, em vez de dar-lhes um cunho puramente nacional" (ASSIS, 1997, v. 3, p. 785).

Não podemos esquecer que em 1813 Sismonde de Sismondi, no seu De la littérature du midi de l'Europe, apresenta argumentos a que treze anos depois Garrett recorrerá. Além de criticar o gongorismo dos poetas portugueses dos séculos XVII e XVIII, Sismondi afirma que a literatura brasileira não se constitui como um corpo autônomo, mas como uma extensão regionalizada da literatura portuguesa. Essa influência é notória quando lemos o que Garrett escreve sobre Cláudio Manuel da Costa. Apesar de notar em muitos de seus versos "vários resquícios de gongorismo e afetação seiscentista”, o Brasil o "deve contar seu primeiro poeta, e Portugal entre um dos melhores” (GARRETT, 1998, p. 56):

[Claudio Manuel da Costa] Deixou-nos alguns sonetos excelentes, e rivalizou no gênero de Metastasio, com as melhores cançonetas do delicado poeta italiano. A que dirige à lira com sua palinódia imitando a tão conhecida do mesmo Metastasio a Nice, Grazie all'ingani tuoi, pode-se apontar como excelente modelo. (GARRETT, 1998, p. 56)

Sobre os versos de Tomás Antônio Gonzaga, Garrett (1998, p. 57) diz que "há dessas liras algumas de perfeita e incomparável beleza: em geral a Marília de Dirceu é um dos livros a quem o público fez imediata boa justiça”. O autor nunca deixa claro o que entende exatamente por Romantismo ou Classicismo (LAWTON, 1974, p. 99). Sabemos que aspectos de ambos os movimentos lhe desagradam. O clássico lhe parece com um "rabugento", "um velho teimoso de cabeleira e polvilhos que embirra em ser taful, e cuida que morrem por ele as meninas". O romântico, além de "desvairado" é um "peralvilho ridículo que dança o galope pelas ruas", tomando "por sorrisos de namorada o supercilioso olhar da senhora honesta que se riu de pasmo de o ver tão doido e tão presumido - mas tão sem-sabor" (GARRETT, v. 1, p. 525). Em outros momentos, não raros, deparamo-nos com tentativas conciliatórias entre essas duas poéticas:

Se o meu assunto é clássico, se o talho e adorno no gênero grego da arte antiga, se invoco sua elegância mitológica, porque não hei de ser eu clássico, porque não hei de afirmar a minha lira pelos sublimes cantores que estremados a tocaram? 
Mas se escolho assunto moderno, nacional, que precisa um maravilhoso nacional, moderno se em vez de lira dos vates, tomo o alaúde do menestrel ou a harpa do bardo, como posso então deixar de ser romântico! (GARRETT, 1904, v. 1, p. 53)

Mas o debateque encontramos no Bosquejo, sobre literatura brasileira, pouco ou nada tem a ver com a liberdade romântica ou a intransigência neoclássica. E mesmo a possibilidade de analisar as obras de Gonzaga, Cláudio Manuel da Costa, Durão ou Basílio da Gama sob a ótica da melhor adequação do tema à forma clássica ou romântica, tal como lemos acima, passa longe. No seu lugar, como já alertamos, a problematização ou o elogio à forma são obscurecidos pela demanda da cor local. Menos importa o estilo de Gonzaga e muito mais que substitua as rosas e os jasmins pelos bagos do cafezeiro.

Se houvesse por minha parte de lhe fazer alguma censura, só me queixaria, não do que fez, mas do que deixou de fazer. Explico-me: quisera eu que em vez de nos debuxar no Brasil cenas da Arcádia, quadro inteiramente europeu, pintasse os seus painéis com as cores do país onde os situou. Oh! E quanto não perdeu a poesia nesse fatal erro! Se essa amável, se essa ingênua Marília fosse, como Virgínia de Saint-Pierre, sentar-se à sombra das palmeiras, e enquanto lhe revoavam em torno do cardeal soberbo com a púrpura dos reis, o sabiá terno e melodioso, - que saltasse pelos montes espessos pela orla da ribeira o tatu escamoso, - ela se entretivesse em tecer para o seu amigo e seu cantor uma grinalda não de rosas, não de jasmins, porém dos roxos martírios, das alvas flores dos vermelhos bagos do lustroso cafezeiro; que pintura, se desenhara com sua natural graça o ingênuo pincel de Gonzaga. (GARRETT, 1998, p. 57)

No caso do Caramuru, Garrett considerava que a forma não foi capaz de ressaltar as cenas que poderiam ter sido pintadas com cores mais fortes e expressões menos afetadas e europeizadas.

$\mathrm{O}$ autor atinou com muitos dos tons que deviam naturalmente combinar-se para formar a harmonia de seu canto; mas de leve o fez; só se estendeu nos menos poéticos objetos; e daí esfriou muito do grande interesse que a novidade do assunto e a variedade das cenas prometia. Notarei por exemplo o episódio de Moema, que é um dos mais gabados, para demonstração do que assevero. Que belíssimas coisas da situação da amante brasileira, da do herói, do lugar, do tempo não pudera tirar o autor, se tão leve não houvera desenhado este, assim como outros painéis?

O Estilo é ainda por vezes afetado: lá surdem aqui ali seus gongorismos; mas onde o poeta se contentou com a natureza e com a simples expressão da verdade, há oitavas belíssimas, ainda sublimes. (GARRETT, 1998, p. 57) 
O mais elogiado por Garrett (1998, p. 59), sem dúvida, foi Basílio da Gama, que "mais nacional foi que nenhum de seus compatriotas brasileiros”. Seu poema, segundo Garrett (p. 58), teria como mérito mostrar:

Cenas naturais muito bem pintadas, de grande e bela execução descritiva; frase pura esem afetação, versos naturais sem ser prosaicos, equando cumpresublimes sem ser guinados; não são qualidades comuns. Os brasileiros principalmente lhe devem a melhor coroa de sua poesia, que nele é verdadeiramente nacional, e legítima americana.

Mesmo que diante da valorização da paisagem americana Garrett relegue para segundo plano qualquer deficiência formal do O Uraguai, isso não significa que seus defeitos lhe passaram desapercebidos:

Mágoa é que tão distinto poeta não limasse mais o seu poema, lhe não desse mais amplidão, e quadro tão magnífico lhe acanhasse tanto. Se houvera tomado esse trabalho, despareceriam algumas incorreções de estilo, algumas repetições, e um certo desalinho geral, que muitas vezes é beleza, mas continuado e constante em um poema longo é defeito. (GARRETT, 1998, p. 58)

A publicação do "Bosquejo", em 1826, coincide com o fim do primeiro exílio de Garrett. Ele passara três anos em Londres, onde mergulhou nas obras de Walter Scott e entrou em contato com o auge da evocação da Idade Média, das ruínas góticas e, principalmente, com a valorização do folclore (SARAIVA; LOPES, 1982, p. 738). Data também desse período o projeto de estabelecer em Portugal uma literatura nacional, inspirada justamente nas tradições locais, no folclore e nos textos anteriores ao predomínio classicista em Portugal. De uma forma ou de outra, o Bosquejo também é fruto desse período de maturação e nacionalização das letras garrettianas. No exílio, pela primeira vez, Garrett foi tocado de modo mais profundo pela necessidade da nacionalidade literária. Anos mais tarde, em 1842, na Introdução do seu Romanceiro, vemos que seu projeto nacionalista ainda persistia:

O que é preciso é estudar as nossas primitivas fontes poéticas, os romances em verso e as legendas em prosa, as fábulas e crenças velhas, as costumeiras e as superstições antigas: lê-las no mau latim moçárabe meio suevo ou meio godo dos documentos obsoletos, no mal português dos forais, das leis antigas e no castelhano do mesmo tempo - que até bem tarde a literatura das Espanhas [sic] foi quase toda uma. O tom e o espírito verdadeiro português esse é forçoso estudá-lo no grande livro nacional, que é o povo e as suas tradições, e as suas virtudes e os seus vícios, e as suas crenças e os seus erros. (GARRETT, 19o8, p. 402) 
Certamente as ideias expostas por Ferdinand Denis nas suas Scènes de la nature sous les tropiques, et de leur influence sur la poésie; suivies de camoens et José Indio e no Résumé de l'histoire littéraire du Portugal, suivi du résumé de l'histoire littéraire du Brésil influenciaram Garrett (MONTEIRO, 1971). Entre os críticos estrangeiros que estudaram e colaboraram com a fundação da literatura brasileira, sem sombra de dúvida Denis é o mais importante brasilianista e lusitanista da primeira metade do século XIX. Gonçalves de Magalhães, por exemplo, assume que para introduzir o Romantismo no Brasil e fundar uma nova literatura segue as instruções de Ferdinand Denis (RIBEIRO, 2012, p. 261). Não é difícil supor as razões que levaram a sua obra, entre a de outros estrangeiros, a ocupar um lugar especial no meio dos intelectuais brasileiros. Ferdinand Wolf, por exemplo, somente publica seu Le Brésil littéraire quarenta anos depois do Résumé de Denis. Já Bouterwek e Sismondi não dissociam a literatura brasileira da portuguesa, o que lhes rende certa antipatia por parte dos brasileiros, além de suas obras serem muito “deficientes" (MOTTA, 1930, p. 269).

Garrett, por sua vez, apesar de ter publicado o Bosquejo em 1826, não costuma ser mencionado como um dos estrangeiros que colaboram para a fundação da literatura brasileira. A primeira razão, segundo Maria Helena Rouanet (1991, p. 182), é que sendo ele português não possuía o mesmo respaldo que Denis, francês, gozava junto aos brasileiros. Depois, fica claro que a postura mais otimista e generosa de Denis diante da possibilidade de existência de uma literatura brasileira autônoma, em contraponto à postura nacionalista-lusitana de Garrett, é a justificativa para que ele caia nas graças da crítica e dos escritores brasileiros.

Apesar de Garrett e Denis aparentemente compartilharem das mesmas ideias sobre o que seria necessário para que o Brasil produzisse uma literatura original, não devem passar em branco as diferenças significativas que observamos nos títulos de suas obras. Primeiramente, ainda que abordada no sexto capítulo do seu ensaio, Garrett não menciona a literatura brasileira no título que dá para o seu longo trabalho: Bosquejo da história da poesia e língua portuguesa. Depois, ao colocar a língua portuguesa em primeiro plano, quando seu objetivo é traçar uma história da literatura, sugere que os outros países que produzem poesia nesse idioma estabeleceriam com Portugal uma relação de derivação ou prolongamento literário, uma vez que seria Portugal o real detentor e proprietário da língua portuguesa. 
Enquanto isso, o título dado por Ferdinand Denis ao seu texto, Résumé de l'histoire littéraire du Portugal, suivi du résumé de l'histoire littéraire du Brésil, explicita uma diferenciação entre a literatura brasileira e a portuguesa, supondo entre as duas um laço literário de familiaridade, mas já de independência. Como diz Maria Helena Rouanet (1991, p. 175), é simbolicamente o uso do termo "suivi" o responsável pelo lugar de destaque que Denis ocupa na fundação da literatura brasileira.

Diferentemente de Denis, que no seu Résumé não apenas propõe, mas entusiasticamente constata que os indícios de nativismo presentes na literatura brasileira desde o tempo colonial são suficientes para sua autonomização, Garrett, como que protegendo as joias da coroa, nega a possibilidade da existência de uma literatura essencialmente brasileira. Ainda que esta defina seus principais traços, permaneceria subjugada à portuguesa, por conta do critério da língua. Como destacam Luiz Costa Lima (1984) e Guilhermino César (1978), Denis é o primeiro a assegurar a independência da literatura brasileira, desmembrando-a da portuguesa: "Enfim a América deve ser livre tanto na sua poesia quanto no seu governo" (DENIS, 1978, p. 36).

É importante lembrarmos que a obra de Garrett e a de Denis, apesar de terem exercido enorme influência no Brasil, num primeiro momento, objetivavam as literaturas de seus respectivos países. A intenção de Garrett com o Bosquejo era traçar uma história da literatura portuguesa de um ponto de vista assumidamente nacional. Depois, corrigir os erros empreendidos por Bouterwek e Sismondi nos seus estudos sobre a literatura do seu país. Já o livro de Denis, as Scènes:

Era uma tentativa de recuperar uma natureza ainda virgem, selvática, aparentemente intocada, habitada por um homem não menos rude e ainda não contaminado de todo pelos valores da cultura ocidental, e que - tanto a natureza, quanto os que lá habitam - poderiam oferecer sugestões temáticas para a renovação das letras francesas. (VIEIRA, 2002, p. 44)

Não se pode deixar de mencionar que na História da literatura de Portugal, seguida da história literária do Brasil, Denis recupera algumas das premissas lançadas anteriormente no seu Lé Brésil e nas Scènes, mas que dessa vez são redirecionadas especificamente para um público português. Se foi decepcionante a repercussão de seus dois primeiros livros, endereçados à França, sua História da literatura de Portugal muda de rota e alcança, ao menos entre os brasileiros, uma popularidade que Denis desde sempre desejou. 
Em 1956, na Revista do Livro, José Osório de Oliveira publica as dezesseis páginas manuscritas, autografadas e não datadas do romance "brasileiro" e inacabado de Garrett: Komurahy - história brasileira.

Quando vemos Garrett, nas décadas de 20 e 30, assim empenhado na criação da literatura "brasileira", isto é, de formas que acolhessem, numa intenção exaltante dos valores autóctones, a realidade física, histórica e moral do grande país-irmão, não podemos deixar de pôr em relevo o papel que lhe caberá na própria gestação do Romantismo brasileiro, que, por esse tempo, começava a definir os seus programas. (MONTEIRO, 1971, p. 323)

Sem apresentar razões que nos façam acreditar nas suas certezas, José Osório de Oliveira (1956, p. 142) não hesita em afirmar que essas poucas páginas foram escritas em 1833 e inspiradas pela convivência que Garrett teve com Manuel Araújo Porto-Alegre, quando ambos moravam em Paris. Diante do enredo indianista empreendido por Garrett e das reflexões de seu herói, que contrapõe a natureza brasileira à tristeza que lhe causam os "gelos pasmados do norte", Ofélia Monteiro também não exclui a possibilidade de Garrett ter iniciado essas páginas durante seu exílio em Paris. No entanto, ela adverte que muito provavelmente esse princípio de romance tenha sido escrito sob o efeito das Scènes, lançado em Paris, em 1824.

É difícil negar que as ideias de Denis tenham exercido forte influência no pensamento e no romance "brasileiro" de Garrett. Isso fica evidente se considerarmos que Komurahy, título do seu romance, é também o nome do personagem principal do texto Os maxacalis, inserido por Denis nas suas Scènes. No seu livro, Denis apresenta episódios que retratam hábitos e costumes de índios brasileiros. Os capítulos XVIII e XIX são dedicados aos maxacalis, tribo à qual pertencia Komurahy, índio e personagem sobre o qual a narrativa se centra.

A história de Denis fala sobre o nativo Komurahy, educado cristãmente por um fidalgo português, chefe da aldeia onde o herói presta seus serviços. O fidalgo morre, e o Komurahy se apaixona de forma correspondida por Helena, filha do novo capitão português, sujeito ambicioso e cruel. Em troca da aprovação de um casamento futuro, o pai de Helena pede ao índio que vá buscar o ouro que há em regiões de difícil acesso da floresta. O trato não é respeitado, e Helena é levada pelo pai para um lugar no qual ninguém pode encontrá-la. Vendo Komurahy com tanta tristeza, os guerreiros de sua tribo raptam Helena e a levam ao seu encontro. Ele, porém, respeita a castidade da moça e a devolve ao seu pai, que mesmo diante da súplica 
dos apaixonados a leva para um lugar distante. Os dois nunca mais voltam a se encontrar. Além de evidentemente criar um pano de fundo com um amor indianista, no final das contas o enredo que tanto seduz Garrett fala de um conflito que perpassará boa parte da obra de Alencar, o duelo entre o cruel colono europeu e o inocente, honrado e puro nativo. Nas poucas páginas do seu Komurahy, Garrett reflete justamente o que ele achava ser fundamental na visão histórica de Denis sobre a decadência da Europa:

Os malefícios das sociedades mal constituídas, como o Portugal histórico tão severamente condenado. Anti-herói, que pactua, para vencer, com as estranhas regras do mundo, o pícaro morre moralmente, sofreria, transformandose, à sua imagem, num ser monstruoso; herói, o índio, sofreria, torturado, a inexequibilidade do seu sonho entre os preconceitos e as cruezas de uma sociedade viciosa e hostil. (MONTEIRO, 1971, p. 319)

Apesar do subtítulo Histórias brasileiras, o olhar do narrador de Komurahy é conscientemente europeu, não querendo em nenhum momento se passar como um americano nativo e acostumado com a paisagem selvagem e exótica brasileira. Garrett não parecia com esse romance querer ensinar aos brasileiros a escrever um romance verdadeiramente brasileiro e indianista, mas sim, construir um romance exótico português, que toma a paisagem selvagem e tropical como motivo literário. Não é demais, nesse caso, acreditarmos que esse projeto inacabado de literatura exótica iria desembocar nas suas Viagens na minha terra.

Denis esteve no Brasil em 1819 e entrou em contato com os maxacalis, que por esse tempo já estavam em extinção. Também não podemos esquecer que tudo indica que, para descrever o exuberante cenário americano, seu exótico indianismo e um catálogo de especificidades da fauna e da flora brasileiras, presentes nas Scènes, Denis utilizou as situações reais narradas pelo príncipe Maximiliano de Wied-Neuwied e pelo botânico Auguste Saint-Hilaire, que respectivamente estiveram nessas mesmas regiões em 1816 e 1819. Segundo Jean-Paul Bruyas (1979, p. LXIV):

Entre a narrativa de Ferdinand Denis e a relação de Neuwied existem analogias de detalhes tais que, apesar da identidade de itinerários - em cerca de trinta léguas brasileiras - seriam necessárias, para explicá-las, coincidências estranhamente repetidas, e, de qualquer modo não justificariam analogias de forma. 
A partir de 1830, tanto o relato do príncipe quanto o do botânico passaram a ser publicados mais detalhadamente em francês, período que coincide com o exílio de Garrett na França. Mesmo que Garrett não tenha entrado em contato direto com o relato de Wied-Neuwied, fê-lo indiretamente via o livro de Denis. Se a isso somarmos que o texto de Denis foi inspiração para o romance inacabado de Garrett, a tese de José Osório de Oliveira de que o Komurahy seria unicamente fruto da convivência com Araújo Porto-Alegre parece não apenas simplificadora, mas também sugestiva de que, como diz Aparecida Ribeiro (1999, p. 119), o crítico dirigia "o seu olhar para um horizonte puramente luso-brasileiro".

Não apenas no Bosquejo Garrett se mostrou um leitor e admirador do Caramuru. Nas primeiras páginas do Komurahy, em meio a reflexões, seu narrador relembra do famoso episódio da "bela Moema, cujos acerbos lamentos repetem ainda os ecos do Recôncavo" (GARRETT, 1984, v. 3, p. 46). Depois, em 1845, na Ilustração: Jornal Universal (1845-1846), Garrett publica o texto "O brasileiro em Lisboa". Nele, numa carta que assina como Jacaré-Paguá, um brasileiro morando há seis meses em Lisboa, escreve a uma Moema imaginária, chamando-a de "caju da minha vida, banana da minha alma, beija-flor de meus pensamentos, ouro-preto da minha saudade", "cana-de-açúcar da minha alma” e "maracujá-açu do meu coração” (GARRETT, 1984, v. 4, p. 43). Sobre a fartura de frutas no Brasil e a escassez em Portugal, o mesmo Jacaré-Paguá diz a sua Moema:

Fazes ideia tu, Moema querida, do que é uma laranjeira aqui? É um mesquinho e rasteiro arbusto comparado com as nossas. Aqui a natureza não coroou o ananás rei das frutas da terra, nem pendurou a jaca ponderosa do capitel dórico de verdura que sustenta a cúpula frondosa dos pomares [...]. (GARRETT, 1984, v. 4 , p. 43 )

A tentativa de Garrett de construir um romance pitoresco foi de novo posta parcialmente em prática com outro romance inacabado, Helena, datadode1854. Dessa vez, além deencontrarmos fragmentos do Komurahy, também estão presentes imagens americanas, a fartura de frutas e plantas, a crítica à escravidão e a presença da extinção da identidade indígena, por consequência do processo colonizador. Mais uma vez, o olhar do narrador, assumidamente estrangeiro, não tenta se passar pelo de um nativo, mas também não se mostra como o de um viajante deslumbrado. Os velhos hábitos "sofisticados" trazidos da Europa, por exemplo, contrastam com o quadro quase expressionista composto pelas flores e abundância de frutos coloridos sobre a mesa. 
Não é difícil reconhecermos em Helena um diálogo com o Caramuru. Se Santa Rita Durão dedica quatro estrofes do seu poema ao maracujá, Garrett toma-o como símbolo do exotismo das formas das frutas tropicais. A presença da cor local, sempre exuberante, oscila entre um tom jocoso, tal como em "O brasileiro em Lisboa", e sério descritivo, como no próprio Komurahy. Além de Denis, Durão e Auguste Saint-Hilaire, em Helena notamos outros interlocutores, como o seu colega de Coimbra Cassiano Espiridião de Mello Mattos e o seu amigo e biógrafo Gomes de Amorim.

Diante dessas brevíssimas pontuações sobre o Komurahy e Helena e tendo em vista a proposta que Garrett delineia para a literatura brasileira, interessa-nos sublinhar a crescente importância que ele atribui ao fator exótico para os romances românticos. Por isso, podemos dizer que, diferentemente de Botelho de Oliveira e Santa Rita Durão, em Garrett, o ufanismo cede lugar ao exotismo.

Apesar de não acreditarmos que Garrett deseje ensinar aos brasileiros como fazer um romance brasileiro, mas apenas aproveitar os motivos exóticos oferecidos por uma terra que até pouco tempo era colônia portuguesa, não se pode desprezar a possibilidade de ele estar lutando contra um francesismo literário. Se para Garrett a literatura brasileira é uma face regionalizada do mundo literário português, nada mais natural, na sua lógica, que patenteá-la e domesticá-la ao seu modo lusitano, ou seja, instituindo o exótico como sua característica essencial. Isso antes que outras formas literárias europeias, como o francesismo, dela se apropriem. Trata-se, na verdade, de mostrar que os caminhos pelos quais a literatura brasileira deve seguir serão traçados por Portugal.

Ainda assim, podemos levar nossas especulações mais adiante e admitir como provável que a exigência garrettiana pela presença da cor local na literatura brasileira seja decorrência de um propósito anterior. Garrett tenta escapar aos poucos dos ensinamentos clássicos que assimilou durante a juventude. A possibilidade de utilizar formalmente o colorido da paisagem brasileira é algo que lhe parece irresistível. O Bosquejo talvez seja o momento crucial no qual irreversivelmente suas concepções clássicas passam a dividir espaço com um novo propósito artístico, a partir do qual a forma literária deve se adaptar à realidade histórica. É possível, no final das contas, que a exuberância da cor local brasileira lhe salte aos olhos, sobrepondo-se inclusive à ideia do tal rito, simplesmente porque contrasta de modo violento com a discreta e incolor mimese clássica. Essa hipótese toma fôlego se levarmos em conta seu projeto inacabado 
de um romance indianista. Por outro lado, lendo Antônio José Saraiva e não esquecendo da relação de mão dupla que Garrett estabelece com o Romantismo e o Classicismo, podemos dizer que a valorização da cor local, da realidade histórica e do caráter nacional lhe permite permanecer relacionado com um dos princípios da arte clássica, o da imitação da natureza, "ou, mais aristotelicamente, dos costumes" (SARAIVA; LOPES, 1982, p. 736).

Mais do que preocupado com a literatura brasileira, ele é impactado pela possibilidade de articular a ideia de uma nova literatura moderna, descritiva e moldada à forma da realidade histórica. O que nos interessa entender é que para Garrett o Brasil, pelo seu clima, vegetação e por culturalmente ainda não estar de todo viciado pela monotonia monocromática neoclássica, poderia ser uma espécie de laboratório para a articulação e atualização prática dessas ideias que lhe surgem como modernizantes. Tanto que sem dificuldades podemos reconhecer toda essa nova proposta, de uma forma ou de outra, em suas Viagens na minha terra e nas Memórias de João Coradinho.

Vejamos um comentário sobre a posição crítica assumida por Garrett entre o Romantismo e o Classicismo:

O Classicismo é uma ordem dada, e o Romantismo, sendo anticlássico, é também uma ordem dada. Desaparece, porém, a dificuldade de admitir para si uma e outra desde que o pensamento as recolha num equilíbrio, opondo uma e outra numa tensão constante, num mesmo lugar que não pode ser senão o momento presente. Porque o presente é aquele lugar em que o eu pensando habita continuamente. (LAWTON, 1974, p. 100)

Definir-se como seguidor, mesmo que crítico e coerente, de qualquer disciplina ou corrente de pensamento implica necessariamente, em alguma medida, deixar-se ser falado por um discurso alheio e impessoal. O sujeito falante, agora falado, assume como suas as palavras de uma gramática ou equação que, se não com muito cuidado, coloca-o numa condição de simples reprodutor alienado de concepções que o dessubjetivam. Esse sujeito vive a ilusão de uma completude e pleno autocontrole e conhecimento, mas na verdade está assujeitado a um saber, por ele mesmo colocado num lugar superior. A formação clássica de Garrett somada à sua gradual, crítica e não deslumbrada adesão ao Romantismo, especificamente àquele exagerado e irracionalista, outorgalhe uma posição privilegiada entre os intelectuais românticos portugueses. No prefácio que escreveu à primeira edição do seu “Camões”, ele diz: 
Não sou clássico nem romântico; de mim digo que não tenho seita nem partido em poesia (assim como em coisa nenhuma); e por isso me deixei ir por onde me levam minhas ideias, boas ou más, e nem procuro converter as dos outros, nem inverter as minhas nas deles. (GARRETT, v. 1, p. XVII)

Com um tom levemente irônico, R. A. Lawton (1974, p. 99) justifica que esse poeta nunca teria se definido como romântico ou clássico, pois "para tanto seria necessário que Garrett forçasse a sua índole, pouco propensa à filosofia e ao raciocínio". De qualquer modo, a sua dupla negação, ao Romantismo e ao Classicismo, constitui um espaço de suposta singularidade a partir do qual ele se recusa a simplesmente ser falado por um outro, seja ele romântico ou clássico. Garrett adotaria, segundo o autor, a postura mais fiel ao seu caráter político e literário:

[...] não se submeter aos preceitos factícios de um classicismo rigoroso, nem abandonar-se ao desprezo revolucionário das verdadeiras regras clássicas, mas conciliar lucidamente, e conforme exigências do assunto, isto é, conforme o momento de criação, ambos os estilos. (LAWTON, 1974, p. 98)

Essa postura o levou a construir, portanto, um discurso, certamente não puro, mas que se propunha a sê-lo. Infelizmente, ao se prender na questão da cor local e da nacionalidade expressiva, Garrett não aborda o nascimento da literatura brasileira com a mesma densidade com a qual assume a condição de intelectual.

Muito mais rico do que se preocupar com a presença ou ausência da cor local, seria problematizar e reconhecer que na poesia árcade, e em alguns dos primeiros românticos, um suposto eu lírico brasileiro ainda não existe, ou ao menos não se faz presente, pois é obliterado por uma remanescente condição europeia. Quando Garrett publica o "Bosquejo”, a literatura brasileira se encontra num estágio intermediário no qual não mais pode simplesmente ser concebida como um prolongamento da portuguesa, mas também ainda não se constituiu enquanto um corpo consciente de suas características fundantes. Os poetas nascidos no Brasil ou que se dizem brasileiros ainda não se sentem plenamente como tal e por isso não falam a partir desse novo possível lugar. Tal consciência nacionalizante, por sinal, não se forjou ao longo dos anos simplesmente com a beleza das matas selvagens americanas. Sobre isso, o psicanalista Octávio Souza (1994, p. 31) dirá que:

A identidade americana só se tornou possível quando o desenraizamento original do homem americano em relação à tradição europeia - sua condição 
utópica - foi "negado", no sentido dialético de negação, por sua repetição, por um outro desenraizamento, desta vez em relação ao próprio solo Americano.

Contudo, na tentativa de ajudar àquele que outrora foi filho, mas que numa virada passa a pleitear o lugar de irmão, falta a Garrett perceber que a existência da literatura brasileira está condicionada não à descrição da cor local, mas à capacidade de os poetas brasileiros reconhecerem ou constituírem uma voz absolutamente diversa daquela que a precedeu, a portuguesa.

\section{GARRETT'S RECEPTION: BRAZIL AND THE BRAZILIAN LITERATURE UNDER THE WATCHFUL EYE OF A ROMANTICIZED CLASSICIST}

Abstract: We intend to demonstrate how Almeida Garrett projected Brazil in his work and problematized the existence of the emergence of a Brazilian and original literature in the nineteenth century.

Keywords: Brazilian Literature; Almeida Garrett; Romanticism.

\section{REFERÊNCIAS}

ALENCAR, José de. Cartas sobre a Confederação dos Tamoios por IG (Publicadas no Diário). Rio de Janeiro: Tipografia Nacional do Diário, 1856.

AMORIM, Francisco Gomes de. Garrett. Memórias bibliográficas. 3 vols. Lisboa: Imprensa Nacional, 1881-1884.

ASSIS, Joaquim Maria Machado de. Instinto de nacionalidade. In: Obras completas de Machado de Assis. 3 vols. Rio de Janeiro: Ed. Nova Aguilar, 1997, pp. 801-8o9.

BAPTISTA, Abel Barros. O livro agreste: ensaio de curso de literatura brasileira. Campinas, S.P: Editora da Unicamp, 2005.

BRAGA, Teófilo. Garrett e os dramas românticos. Porto: Lello \& Irmão, 1905.

BRUYAS, Jean-Paul. Introdução. In: DENIS, Ferdinand. Os maxacalis. São Paulo: Conselho Estadual de Cultura, 1979.

CASTRO, Aníbal Pinto de. Garrett: um dramaturgo moderno, leitor de clássicos. In: Camões, Revista de Letras e Culturas Lusófonas, Lisboa, n. 4, jan./mar. 1999, pp. 33-44.

CÉSAR, Guilhermino (org.). Historiadores e críticos do Romantismo. I. A contribuição europeia, crítica e história literária. São Paulo: Editora da Universidade de São Paulo, 1978. 
DENIS, Ferdinand. Resumo da história literária do Brasil. In: CÉSAR, Guilhermino (org.). Historiadores e críticos do Romantismo. I. A contribuição europeia, crítica e história literária. São Paulo: Editora da Universidade de São Paulo, 1978, pp. 27-79.

GARRETT, Almeida. Obras completas. 2 vols. Lisboa: Empresa da História de Portugal, 1904 .

GARRETT, Almeida. Obras completas. 14 vols. Lisboa: Círculo de Leitores, 1984.

GARRETT, Almeida. Bosquejo da História da Poesia e Língua Portuguesa. In:ZILBERMAN, Regina (org.). O berço do cânone: textos fundadores da história da literatura brasileira. Porto Alegre: Mercado Aberto, 1998, pp. 18-73.

HERCULANO, Alexandre. Elogio histórico de Sebastião Xavier Botelho. In: Opúsculo IX. Lisboa: Tipografia da Antiga Casa Bertrand, 1909. Disponibilizado em formato eletrônico pelo Projeto Gutenberg. disponível em: <http://www.gutenberg.org>.

LAWTON, R. A. O conceito garrettiano do romantismo. In: Estética do Romantismo em Portugal. Primeiro Colóquio 1970. Lisboa: Centro de Estudos do séc. XIX do Grémio Literário, 1974, pp. 95-104.

LIMA, Luiz Costa. Sociedade e discurso ficcional. Rio de Janeiro: Ed. Guanabara, 1986.

MONTEIRO, Ofélia Paiva. A formação de Almeida Garrett. Experiência e criação. 2 vols. Coimbra: Centro de Estudos Românicos, 1971.

MOTTA, Arthur. História da literatura brasileira. São Paulo: Ed. Nacional, 1930.

NUNES RIBEIRO, Santiago. Da nacionalidade da literatura brasileira. In: COUTINHO, Afrânio (org.). Caminhos do pensamento crítico. V. 1. Rio de Janeiro: Ed. Americana/ Prolivro, 1974, pp. 30-61.

OLIVEIRA, José Osório de. Um Garrett brasileiro; influência do Brasil em Portugal. Revista do Livro, Rio de Janeiro, ano 1, n. 1-2, 1956, pp. 137-143.

RIBEIRO, Maria Aparecida. Imagens do Brasil na obra de Garrett: invocações e exorcismos. In: Camões, Revista de Letras e Culturas Lusófonas, Lisboa, n. 4, jan/mar. 1999, pp. $115-127$.

RIBEIRO, Maria Aparecida. Herculano, o rei e o amigo do rei: a polêmica sobre a Confederação dos Tamoios. In: Uma coisa na ordem das coisas. Estudos para Ofélia Monteiro. Coimbra: Imprensa da Universidade de Coimbra, 2012, pp. 305-320.

ROUANET, Maria Helena. Eternamente em berço esplêndido: a fundação de uma literatura nacional. Prefácio Luiz Costa Lima. São Paulo: Siciliano, 1991.

SARAIVA, António José. A poesia brasileira em Portugal. Terceira Margem: Revista do Centro de Estudos Brasileiros, Porto (Universidade do Porto, Faculdade de Letras, Centro de Estudos Brasileiros), v. 3, 2002, pp.7-14. 
Remate de Males, Campinas-SP, v.38, n.2, pp. 960-989, jul./dez. 2018 - 989

SARAIVA, António José; LOPES, Oscar. História da literatura portuguesa. 12. ed. Porto: Porto Editora, 1982.

SOUZA, Octavio. Fantasias do Brasil: as identificações na busca da identidade nacional. São Paulo: Escuta, 1994.

VIEIRA, Anco Márcio Tenório Vieira. Entre Tupã e a Cruz de Malta: a autonomia literária e a defesa do conceito de literatura luso-brasileira no século XIX - 180o-1870. UFPB. Tese de Doutorado, 2002.

ZILBERMAN, Regina (org.). O Berço do cânone: Textos fundadores da história da literatura brasileira. Porto Alegre: Mercado Aberto, 1998. 